\title{
Rare metals, unconventional resources, and sustainability
}

$\operatorname{AUTHOR}(S):$

McLellan, Ben; Corder, Glen; Ali, Saleem; Golev, Artem

\section{CITATION:}

McLellan, Ben ...[et al]. Rare metals, unconventional resources, and sustainability. Special Paper of the Geological Society of America 2016, 520: 57-65

\section{ISSUE DATE:}

2016-05-01

URL:

http://hdl.handle.net/2433/246272

\section{RIGHT:}

Copyright (C) 2016, The Geological Society of America (GSA), Inc. All rights reserved.; 許諾 条件に基づいて掲載しています。;この論文は出版社版でありません。引用の際には出 版社版をご確認ご利用ください。; This is not the published version. Please cite only the published version. 


\section{Rare metals, unconventional resources and}

\section{sustainability}

\section{Authorship with contact information}

Ben McLellan (Kyoto University, Graduate School of Energy Science /University of Queensland, Sustainable Minerals Institute, Centre for Social Responsibility in Mining)

E-mail: b.mclellan@energy.kyoto-u.ac.jp Phone: +81 757539173

Glen Corder (University of Queensland, Sustainable Minerals Institute, Centre for Social Responsibility in Mining)

E-mail: g.corder@smi.uq.edu.au Phone: +61 401994948

Saleem Ali (University of Queensland, Sustainable Minerals Institute, Centre for Social Responsibility in Mining / Rubenstein School of Environment and Natural Resources, University of Vermont)

E-mail: s.ali3@uq.edu.au Phone: +61 733464043

Artem Golev (University of Queensland, Sustainable Minerals Institute, Centre for Social Responsibility in Mining)

E-mail: a.golev@uq.edu.au Phone: +61 733464041

\section{Abstract}

Recent expansion in the demand for clean energy and efficient technologies has led to demand for a variety of exotic, rare or "strategic" metals. Some of these are physically rare, while others are economically or politically unavailable. In order to fill the gap between supply and demand, and to ensure future resources, various unconventional resources are being examined. This chapter discusses deep 
ocean and industrial ecology-based solutions for providing these materials, and provides considerations of how such resources can be considered within a framework of sustainable development. Specifically, the paper addresses the importance of the social elements of the rare metals supply chain, examining the elements of local stakeholder impact and the broader, global public interest that the technologies utilising such metals represent. The paper also considers how technical and environmental knowledge derived from geosciences can have an impact on stakeholder support for alternative resources.

\section{INTRODUCTION}

Although the concept of strategic or critical minerals has been around for many years, there has been an increase in interest in such materials over the last 5-10 years, due to the confluence of a number of global social, political, economic and industrial trends.

There are various specific definitions, but in general, minerals are considered to be critical if there is the potential for supply disruption, and if the impact of that supply disruption on an economy, nation or industry would be high (American Physical Society and The Materials Research Society, 2011, European Commission, 2010). The threat of supply disruption can be associated with: centralisation of supply (typically leaving control of primary resources in the hands of one or a few countries or companies), political risk of supplier nations (volatile governments, volatile diplomatic relationships, manipulation of markets), increasing demand and market competition (price rises or price volatility, reduced availability), decreasing supply (depletion of reserves, market failure to provide adequate financial return, political restrictions on production, environmental or social license retraction). Supply chains are generally weakest when there are only a small number of suppliers (supply monopolisation or a high level of centralisation) and substitutes are not locally available (McLellan et al., 2012). On the other hand, the impact of supply disruption is often related to military needs or security of specific economic sectors, but can also be relative to important infrastructure and technology in general society.

The rise in discourse around critical minerals has been driven by the combined influence of a number of key factors (as mentioned above). The most prominent among these have been: (a) the expanded use of minor metals providing functionality in new energy and electronics technology; (b) the rising demand of 
such metals from rapidly developing countries in addition to the rise associated with developed countries; (c) realisation of the tenuousness of supply chains and the importance of particular nations as near-monopoly suppliers within those supply chains; (d) specifically in the case of Rare Earth Elements (REE), the role of China as dominant supplier, major consumer and its willingness to use governmental control of supplies to affect markets; (e) volatile metal prices in markets, not only associated with the global financial crisis and its aftermath.

The countries or regions that have been most central to this discussion of critical minerals include Japan (as a resource poor nation, constantly seeking to secure supplies and more cautious than most other countries in this regard), USA (with large economic dependence and military-specific discussions of critical minerals), the European Union (EU) (with large economic dependence and moderate internal resource), and even China (largest producer of most minerals, but also largest consumer) (McLellan et al., 2013). The United Kingdom (UK) and South Korea have also entered the debate, while countries such as Australia are keen to tout their new and existing resources as suppliers to fill any gap between demand and supply (Skirrow et al., 2013).

The materials listed as critical by various countries are shown in Table 1, illustrating the wide range and variation in what is classified as critical or strategic. Importantly, the list of such materials varies from nation to nation and year to year, based on local economic and political factors. As with most innovation, criticality (or necessity) has driven some commodities off the list, as downstream companies develop alternative technologies or substitute materials. 
TABLE 1. CRITICAL MINERALS AS LISTED IN MAJOR COUNTRY REPORTS. SOURCES: (Bauer et al., 2010, European Commission, 2010,

Skirrow et al., 2013, USDOE, 2012)

\begin{tabular}{|c|c|c|c|c|c|c|}
\hline \multirow[t]{2}{*}{ Material } & \multicolumn{2}{|l|}{ EU } & \multirow[t]{2}{*}{ USA } & \multirow[t]{2}{*}{ Japan } & \multirow[t]{2}{*}{ South Korea } & \multirow[t]{2}{*}{ UK } \\
\hline & 2010 & 2013 & & & & \\
\hline Antimony & $\checkmark$ & $\checkmark$ & & $\checkmark$ & $\checkmark$ & $\checkmark$ \\
\hline Arsenic & & & & & & $\checkmark$ \\
\hline Barium & & & & & & $\checkmark$ \\
\hline Beryllium & $\checkmark$ & $\checkmark$ & & & & $\checkmark$ \\
\hline Bismuth & & & & $\checkmark$ & & $\checkmark$ \\
\hline Borates & & $\checkmark$ & & & & \\
\hline Chromium & & $\checkmark$ & & $\checkmark$ & $\checkmark$ & \\
\hline Cobalt & $\checkmark$ & $\checkmark$ & & $\checkmark$ & $\checkmark$ & $\checkmark$ \\
\hline Coking coal & & $\checkmark$ & & & & \\
\hline Copper & & & & $\checkmark$ & & \\
\hline Fluorspar & $\checkmark$ & $\checkmark$ & & $\checkmark$ & & \\
\hline Gallium & $\checkmark$ & $\checkmark$ & $\checkmark$ & $\checkmark$ & $\checkmark$ & $\checkmark$ \\
\hline Germanium & $\checkmark$ & $\checkmark$ & & $\checkmark$ & & $\checkmark$ \\
\hline Indium & $\checkmark$ & $\checkmark$ & $\checkmark$ & $\checkmark$ & $\checkmark$ & $\checkmark$ \\
\hline Lithium & & & $\checkmark$ & $\checkmark$ & $\checkmark$ & \\
\hline Magnesite & & $\checkmark$ & & & & \\
\hline Magnesium & $\checkmark$ & $\checkmark$ & & $\checkmark$ & $\checkmark$ & $\checkmark$ \\
\hline Manganese & & & $\checkmark$ & $\checkmark$ & $\checkmark$ & \\
\hline Mercury & & & & & & $\checkmark$ \\
\hline Molybdenum & & & & $\checkmark$ & $\checkmark$ & $\checkmark$ \\
\hline Natural graphite & $\checkmark$ & $\checkmark$ & & $\checkmark$ & & $\checkmark$ \\
\hline Niobium & $\checkmark$ & $\checkmark$ & $\checkmark$ & $\checkmark$ & $\checkmark$ & $\checkmark$ \\
\hline Nickel & & & & $\checkmark$ & $\checkmark$ & \\
\hline Platinum Group Metals (PGMs) & $\checkmark$ & $\checkmark$ & $\checkmark$ & $\checkmark$ & $\checkmark$ & $\checkmark$ \\
\hline Phosphate rock & & $\checkmark$ & & & & \\
\hline Rare Earth Elements (REEs) (Heavy) & $\checkmark$ & $\checkmark$ & $\checkmark$ & $\checkmark$ & $\checkmark$ & $\checkmark$ \\
\hline Rare Earth Elements (REEs) (Light) & $\checkmark$ & $\checkmark$ & & $\checkmark$ & $\checkmark$ & $\checkmark$ \\
\hline Selenium & & & & & $\checkmark$ & $\checkmark$ \\
\hline Silicon metal & & $\checkmark$ & & & $\checkmark$ & \\
\hline Strontium & & & & & & $\checkmark$ \\
\hline Tantalum & $\checkmark$ & & & $\checkmark$ & $\checkmark$ & \\
\hline Titanium & & & & & $\checkmark$ & \\
\hline Tungsten & $\checkmark$ & $\checkmark$ & & $\checkmark$ & $\checkmark$ & $\checkmark$ \\
\hline Vanadium & & & & $\checkmark$ & $\checkmark$ & \\
\hline Zinc & & & & $\checkmark$ & & \\
\hline Zirconium & & & & & $\checkmark$ & \\
\hline
\end{tabular}


In 2013, the US Department of Energy launched the "Critical Materials Institute," a \$120 million undertaking headquartered at the Ames Research Centre in lowa alongside a host of 17 other government labs, universities and industry partners. This is a laudable effort to invest in research on minerals that are essential for modern technological advancement and whose supply is likely to be constrained in coming years. However, the motivation behind this effort may in large part be attributed to concerns over continuing Chinese dominance in rare earth minerals, and the prospective Bolivian dominance in lithium (Bolivia has identified resources greater than Chile, but not yet in production (USGS, 2015)).

Rare earth elements (REEs) are a group of 17 elements mostly from the lanthanide series in the periodic table that are usually found together in similar mineral ores. More than $90 \%$ of all "rare earth" minerals are currently mined in China. The supply constriction on these minerals in 2012 led to a trade dispute being lodged by the US, EU and Japan against China in the World Trade Organization (WTO). China`s arguments that supply was constricted to account for environmental clean-up at mine sites was rejected, and the WTO ruled against China, who subsequently removed their export quotas (Nekuda Malik, 2015) one reason why the price of REEs has subsequently dropped dramatically (USGS, 2015). Although the extraction of these elements incurs some ecological stress, including production of radioactive thorium waste, rare earths are essential for "green economy" infrastructure (Ali, 2014). Yttrium and associated rare-earth elements neodymium, europium, terbium, and dysprosium are used in permanent magnets (for high-efficiency motors) and advanced-lighting systems.

Similar to the rare earths dominance of China, almost half of all lithium reserves are currently believed to be in South America. The ubiquitous use of lithium batteries in transportation and consumer electronics is unavoidable, despite the challenges faced by the Boeing Dreamliner (Williard et al., 2013). The element has an unparalleled ability to form compounds which can store energy in low weight and volume as it is the lightest metal on the periodic table.

Local and regional development throughout the world depends on energy, especially electricity access which one fifth of the world's population still lacks and which is required to provide lighting - a vital 
development precursor (IEA, 2010, Kanagawa and Nakata, 2008). Minerals such as the rare earths and lithium play an essential role in clean and affordable energy delivery and usage

\section{Reserves of critical minerals}

Reserves of critical minerals vary over many orders of magnitude, as do their production flows. Table 2 summarises the reserves and mine production data for the readily accessible critical minerals statistics. This data must be considered with the understanding that some of these materials are by-products of major minerals (e.g. Gallium) or refinery by-products (e.g. Indium), and that in some cases the restrictions on supply are not based on the reserves or mine production rate, but rather on ability to process materials at the intermediate stages of the supply chain.

Centrality of supply is certainly an obvious and important factor in criticality, but the influence of enduser country factors is also readily-evident from the production data (even if it was not already made specific in the definition). The static depletion index (reserves to production ratio, $\mathrm{R} / \mathrm{P}$ ) in Table 2 makes it apparent that physical scarcity at the global level is not the main concern. 
TABLE 2. RELEVANT DATA ON SELECTED CRITICAL MINERALS (DATA: (USGS, 2013))

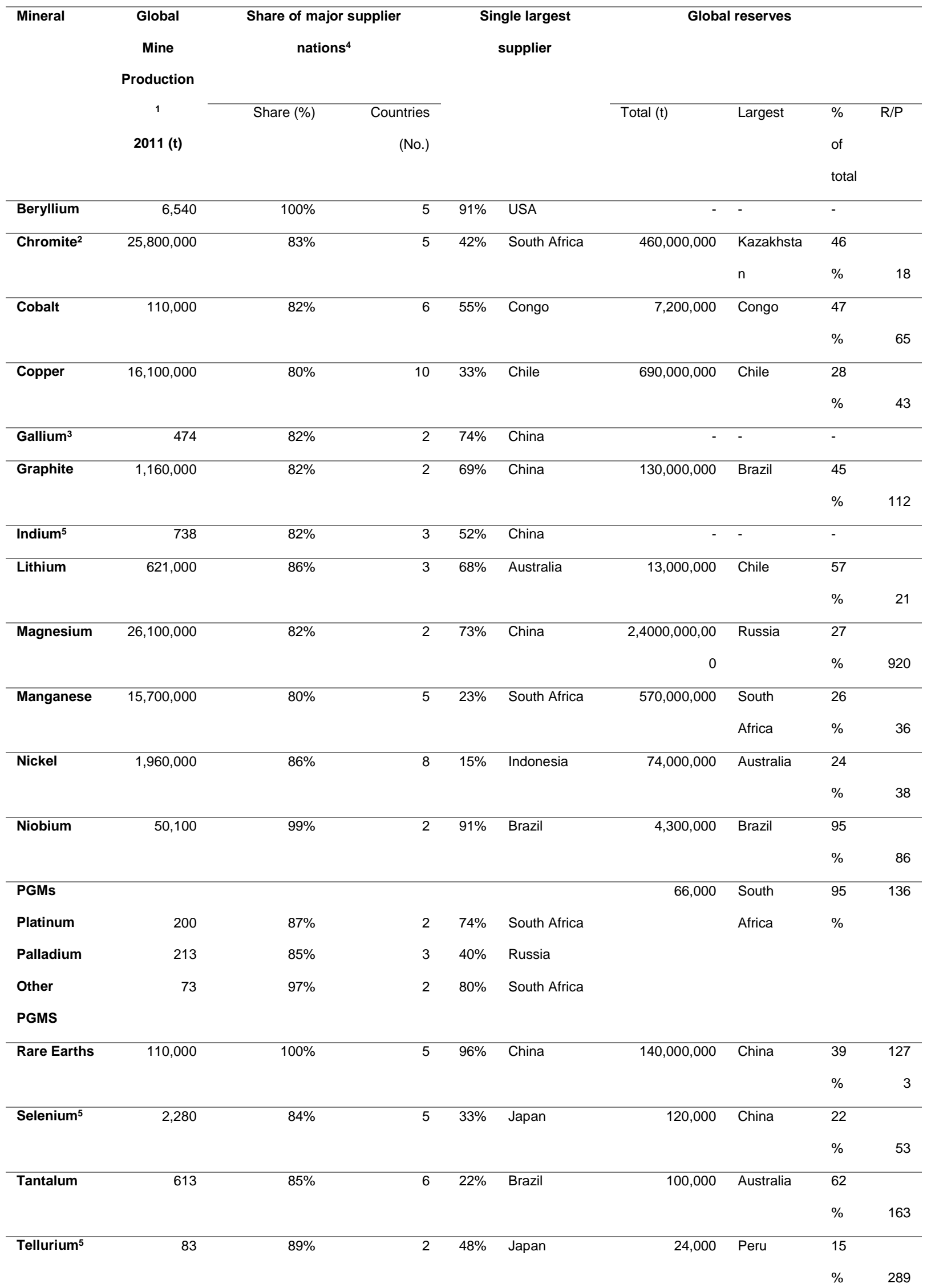




\begin{tabular}{|c|c|c|c|c|c|c|c|c|c|}
\hline Tungsten & 67,700 & $89 \%$ & 2 & $85 \%$ & China & $3,500,000$ & China & 54 & \\
\hline & & & & & & & & $\%$ & 52 \\
\hline \multirow[t]{2}{*}{ Vanadium } & 74,000 & $98 \%$ & 3 & $49 \%$ & China & $14,000,000$ & USA & 36 & \\
\hline & & & & & & & & $\%$ & 189 \\
\hline \multirow[t]{2}{*}{ Zinc } & $12,600,000$ & $83 \%$ & 9 & $32 \%$ & China & $250,000,000$ & Australia & 26 & \\
\hline & & & & & & & & $\%$ & 20 \\
\hline
\end{tabular}

Notes:

${ }^{1}$ Mine production refers to metric tonnes of contained metal content unless otherwise specified

${ }^{2}$ Chromite is reported as ore (not metal content)

${ }^{3}$ Gallium expressed as capacity for production as it is a by-product mineral

${ }^{4}$ Number of producer countries comprising $80 \%$ or more of world supply

${ }^{5}$ Selenium, Tellurium, Indium figures are the refinery production rate

It is evident that the centralisation of supply is not always associated with dominance in reserves, and indeed it is mostly the traditional resource-exporting countries that dominate in both production and reserves. Reserves are likely to be more rigorously understood in these countries, where exploration has been much wider over (generally) a longer period of time, and global reserves are likely to be much higher. In the near term, consideration of reserves and production in "frontier" countries is not likely to have any impact on the level of criticality, as the insufficiency of existing infrastructure and often the socio-political environments make the likelihood of rapid investment and short term production unlikely.

\section{Resource potential from unconventional supplies}

Given the global growing demand for minerals and metals and the shift of mining from developed to developing countries as well as the general trend of decreasing ore grades, there is now a greater emphasis from concerned nations to source metals from alternative sources. In this study we consider the impact of two potential alternative supply sources that are receiving significant attention - recycling and deep ocean resources. These are not the only potential new sources of minerals, as mentioned above, the non-traditional mining countries, and less-developed, typically less-explored regions of the world are gradually becoming more attractive to major mining companies whose traditional territories are facing decreasing grades and often increasing economic barriers to entry (Corder et al., 2012a). 
One important area that is receiving significant attention is recycling and re-use of metals from end of life products and waste streams. Initiatives such as the Circular Economy in China (Geng et al., 2012) and in Europe (Ellen Macarthur Foundation, 2012), which aim to move away from the traditional linear system model of consumption, are gaining much traction. These initiatives are the application of industrial ecology concepts, which uses nature as a metaphor, and closely examines the opportunities to reuse and recycle different waste streams arising in industrial and consumer activities, as well as reorganizing the industrial systems to ensure resource efficiency and resilience (Corder et al., 2014).

The extraction and recovery of rare earths from unconventional resources has received attention recently, due to such factors as increasing demand, price fluctuations and constraints on supply of conventional resources. Investigations into the recovery of rare earths have included recycling of low value waste streams such as bauxite residue, phosphogypsum, waste water, slag and mine tailings as well as end-oflife batteries, fluorescent lamps and magnets (McLellan et al., 2013). Other waste streams such as coal ash (Seredin et al., 2013) have also found interest, particularly during the recent period of very high REE prices.

The amount of recycled REEs has been estimated as low as 1\% for the end-of-life products until 2011 (Binnemans et al., 2013, UNEP, 2013). However, there have been several recent developments in recycling technologies for REE contained lamp phosphors, magnets, NiMH batteries, and polishing powders, introduced in Europe by Umicore, Solvay, and Hydrometal, in Japan by Honda, Mitsubishi, Hitachi, and others, in Vietnam by Showa Denko KK, and in China by Ganzhou Rare Earth Group (Ferron and Henry, 2013). Many of the recycling methods used to date are very similar to the processes used for the initial generation of primary materials - hence the only savings in energy and environmental impact are often the savings from the mining stage. With regards to the energy and emissions impacts, the mining stage tends to be low impact with respect to the overall process lifecycle, and recycling using current methods is therefore unlikely to lead to large environmental benefits in these categories, however the impact on land use and other categories may be high in the mining stages, making recycling an attractive option. It is only the current period of high prices that makes recycling of minor metals economically feasible, although from a resource conservation perspective it is a valuable activity. Unlike 
the benefits of recycling many of the base metals with large circulation and low alloying or relatively easy separation, the minor metals are less easily collected and separated when they are present in "urban ore" such as mobile phones (Graedel et al., 2011), and the system of collection is an important aspect in developing this unconventional source (Moura Bernardes et al., 2003, Tanskanen, 2013).

Despite scarce information in the public domain about volumes of REE recycling, we believe that these activities have notably progressed over the last few years and perhaps account for at least $5 \%$ (pre and post-consumer recycling) of current rare earths supply. It is likely just a matter of time to recognise the scale and impact of different REE recycling operations on the market, when all these initiatives will become less sensitive to disclose the commercial data, and the rare earth market and supply become more diversified and secure.

The other unconventional source considered here is that of deep sea mining. It has been indicated that there are a wide range of critical metal-bearing materials in the deep ocean, including REE in deep ocean muds throughout parts of the Pacific (Kato et al., 2011). As with many new land-based deposits, deep ocean resources are generally polymetallic mixtures that are unlikely to be mined solely for the grade of a single contained metal (May et al., 2012). Such resources have been known for over 100 years, and have been seriously investigated since at least the 1970 `s, however, up till now there has not been sufficient economic impetus to promote their extraction (Martino and Parson, 2012). Despite the prospect of the Solwara I project starting production in Papua New Guinea in 2016 (Nautilus Minerals, 2013), it is still unclear whether commercially feasible operations can be developed. It has also been estimated that based on just the mining activity, the embodied energy and emissions of deep ocean mining is likely to be 2-4 times the average of land-based operations, with the pumping requirements of deeper resources exacerbating this (McLellan, 2014).

Deep sea muds in Japan`s Exclusive Economic Zone (EEZ) are being targeted as potential high grade REE resources, which may have grades at least three to five times those of onshore Chinese ion-exchange clay deposits, with sections of much higher grade (Kato et al., 2011). Techniques for selective concentration of these ores using relatively inexpensive technologies are being developed with the potential for increasing 
the effective grades further, although this must be balanced against the cost of extraction from more than $5000 \mathrm{~m}$.

Unlike recycling, which fulfils multiple purposes - retention of valuable materials within the economy, securing supply and effective waste disposal - deep ocean mining is likely to face much higher hurdles to gain a social license to operate, although this will no doubt be context-specific. In recent research it has been indicated that very few Australians would currently support deep ocean mining, due to fears of environmental damage and the sense that on-land mining is sufficient at present (Mason et al., 2010). On the other hand, Japan`s government is promoting deep ocean mining (Government of Japan, 2013) as a source of resources in a country that has very little of its own on land, which may sway stakeholder opinion.

\section{SUSTAINABILITY CONSIDERATIONS IN CRITICAL RESOURCES}

This section will discuss some of the key issues important to sustainability of critical resources. To avoid circular discussions on sustainability and the mining industry such as "how can the mining/minerals industry be sustainable given it is extracting a finite resource?", it is necessary to understand the industry's role in contributing to societal sustainability. In this sense the term sustainability with regard to the industry is not about "sustaining" mining but understanding how a mine and the industry more broadly can make a proper contribution to societal sustainability. It can achieve this by improving the extraction and use of minerals, the integration and continued substitution of new materials with end of life recycling and the synergistic development of social and environmental benefits rather than impacts (Corder et al., 2012b).

Over the last generation the mining and minerals industry has increasingly implemented actions and initiatives aimed at delivering good sustainability practice. To a large part, the foundation of the current industry's commitment to sustainable development was established over a decade ago by the "Mining, Minerals and Sustainable Development" (MMSD) project, its publication "Breaking New Ground" in 2002 (IIED, 2002) and the subsequent adoption of the International Council on Mining and Metals' (ICMM) 10 principles in 2003(ICMM, 2003). These principles, plus other voluntary codes, such as the Equator 
Principles and UN Global Compact, and reporting mechanisms, such as the Global Reporting Initiative and Dow Jones Sustainability Index, have underpinned individual mining companies' own sustainable development approaches and policies and have provided a framework for implementing initiatives that fall under the broad umbrella of sustainable development. There is a wide range of case studies that demonstrate examples of good practice in industry, although with growing societal expectations as well as increasing demands for energy, water and land access and use, there is a need for the industry to continually improve its sustainability performance into the future.

There is a growing body of evidence that sustainability issues are affecting the core activities of mining and minerals industry projects and operations. Recent research has highlighted that most extractive companies do not currently identify, understand and aggregate the full range of costs related to conflict with local communities (Davis and Franks, 2014, Franks et al., 2014). The most commonly occurring costs were related to lost productivity due to temporary shutdowns or delays. As an indication, costs of approximately US\$20 million per week in Net Present Value (NPV) would be incurred due to delayed production for a project of capital expenditure of between US\$3-5 billion (Franks et al., 2014). A recent review of the mining industry found that $36 \%$ of the respondents indicated that public opposition to mining affected the permitting and/or approval process of their projects, with $21 \%$ of the $36 \%$ stating that their permitting and/or approval process was rejected (Fraser Institute, 2013). Furthermore, 'social licence to operate' was recently considered to be in the top three business risks facing the mining and metals industry (Ernest and Young, 2014). In addition, the difficulty for mining operators to gain acceptance is the broadening in the number and variety of affected stakeholders, the growing public understanding of the wider impacts of extractive industries and the improved ability of the public to access and disseminate information through technology (Ernest and Young, 2014). The results of the abovementioned studies illustrate that sustainability considerations are now strongly influencing business performance and need to be better integrated into overall business decision-making processes for the extraction of resources.

Whilst the above descriptions may be generalizable across the entire minerals industry, sustainability 
from the perspective of critical minerals requires some further specific comments. Critical minerals have been largely identified for their particular functional properties and subsequent important role in society and the economy. Some, such as copper, are widely utilised across various industries, while others are more closely aligned with a single industry or application (e.g. Europium in LEDs). While their current criticality may be seen as an indicator of their importance for the sustainability of a specific society or economy, the time variability of this indicator and the inherent vulnerability associated with criticality is perhaps a counter-argument. The economic dependence of certain nations on particular minerals is largely a function of their current economic structure and existing technology mix, which may be unsustainable inherently. On the other hand, many critical minerals are crucial to environmentally beneficial technologies - for example in clean energy technologies, such as Neodymium and Dysprosium (permanent magnets for wind turbines and electric vehicles), Lithium (light weight batteries for electric vehicles and other electronics), Yttrium and PGMs (hydrogen fuel cells). In this context, the contribution of critical minerals to sustainability (at least in the operational phase) is considered highly important, and has been a major driver in criticality studies (Hoenderdaal et al., 2013).

\section{Unconventional resources and sustainability}

The interest in developing unconventional resources is driven by several factors, including concerns for the lack and/or exhaustion of primary geological resources, security of supply for critical metals vital to modern technologies and military applications, and technological advances allowing developing nations to overcome some general economic and environmental burdens.

Primary mining and processing of critical metals usually result in significant environmental impacts. For example, the processing of rare earths is characterised by high levels of water consumption, energy inputs, chemicals use, as well as separate treatment and disposal of radioactive waste materials (EPA, 2012). The low grade of many deposits of these materials is one factor in this, as is the difficulty of separating chemically and physically similar components - particularly in the case of REEs and PGMs (Gupta and Krishnamurthy, 2005). The high environmental impacts of sourcing rare earths from conventional mining and processing (Tharumarajah and Koltun, 2011) provide an incentive to seek 
unconventional sources. However, as mentioned above, the current recycling techniques do not provide a significant improvement on the primary resource impacts, and the system of waste collection, separation and disassembly require infrastructural and institutional improvements as well as behavioural change from consumers and processers. There is no doubt that recycling could offset some of the rare earths primary supply, however the ecological footprint and economic costs for recycling still can be significant. The removal of mercury from lamp phosphors which contain the heavy rare earths europium, terbium and yttrium, requires complicated, energy intensive equipment and there have been no studies on recovery of rare earths from LCD backlights which also contain mercury (Buchert et al., 2012). Nevertheless, recycling can offer an opportunity to reprocess the most desired elements, specifically targeting products with high concentration of certain valuable critical metals (McLellan, 2015). Moreover, there is still a significant potential for better product design for recycling where improvements will help to increase the recovery rates and efficiency of recycling (UNEP, 2013).

The growing application of critical metals in the modern hi-tech products also leads to a larger "resource base" of critical metals in the end-of-life products. In contrast to below-ground deposits, urban mines are growing reserves to be exploited, although the combination of different materials, miniaturisation and the improvement of technologies in the production phase can lead to a decreasing "grade" within these reserves. The ability to effectively disassemble and select the urban ore components with high grade e.g. the magnets from wind turbines rather than the entire turbine - is important to the effectiveness, efficiency and ultimate recovery of secondary resources. Improvements in product design and recovery technologies will potentially create new opportunities to secure the supply of critical metals from recycled sources, but a life cycle approach should be implemented in order to better optimise the recoverability from end-of-life stock.

In the case of deep ocean mining, the uncertainties of the operating environment translate into contention and widely varying opinions of the potential sustainability. From the perspective of mining, deep ocean deposits have a number of advantages - they are typically near the surface of the ocean floor requiring minimal overburden removal, explosives are not required, and they often contain high ore 
grades - including many critical minerals such as cobalt, zinc, copper, PGMs and REEs (Siddiquie et al., 1984, Kato et al., 2011). However, some of the deposits (particularly active hydrothermal vents) are considered to have highly unique, specialised ecosystems - and whilst it is likely that such sites will be preserved and "mined-around", there is still some concern raised (Ellis and Macdonald, 1998). Moreover, the lack of oxygen and light and the high pressure of the deep ocean environment mean that much of the benthic fauna is largely immobile, which implies that rehabilitation can be complex and disturbance is likely to induce irreversible, although localised, change (Sharma et al., 2000). It is also important to consider that the release of waste material (waste water and sediment), although expected and designed to be released below the depths at which most biodiversity is found, will have impacts associated with "blanketing" the seabed and if incorrectly undertaken could be re-suspended or even brought upwards in the water column through the influence of currents.

In addition to the relatively unknown environmental impacts of deep ocean mining, the challenges of mining itself must be considered. Early estimations indicate that the mining stage requires significantly more energy than average on-land deposits to extract (due to the pumping of materials from depth and the requirement to keep the production vessel in a relatively fixed location) - this could be 2-4 times the average energy, and certainly comparable to deep land-based mines (McLellan, 2014). Exacerbating the impact of this energy use is the fact that deep ocean mining operations utilise ship-board power, generated by the use of fuel oil or diesel. Technologies to offset this must be considered in order to improve the overall sustainability of such resources. The advantages of high grades and low wastes may help the life cycle impacts in some cases, if the processing energy is reduced, but a full lifecycle assessment (LCA) is yet to be completed.

From the perspective of societal stakeholders, unconventional resources are typically considered quite differently from conventional resources. The recycling of end-of-life products is often also supported by general public opinion, thus can be considered as a part of responsible manufacturing to meet customers' expectations. By contrast, public support for deep ocean mining is less certain, and perhaps less likely particularly in near-shore projects (Mason et al., 2010). The specific stakeholders needing to be consulted within the deep ocean context are also uncertain, particularly in the remote EEZ or in international 
waters. The procedures for environmental impact assessment, and the associated social impact assessment and consultation are still in development at the international level.

Adding further complexity to the economic argument for recycling is the dispersed nature of end use technologies. Even in the case of large-scale renewable energy power plants, the geographical dispersion and the small scale of deposits are likely to place significant pressure on the potential feasibility of recycling (McLellan, 2015).

\section{CONCLUSIONS}

Critical minerals can have an important impact on sustainability through their use in new energy and electronic technologies to reduce environmental impacts of society. However, the limitations of supply chains may be tested as demand continues to rise. Meeting the energy needs of the world's most deserving and impoverished inhabitants and maintaining high living standards in the developed world, while keeping within the ecological limits of the planet, will require making critical mineral supply chains less fragile - through a combination of increased and diversified supplies and reduced demand (Alonso et al., 2012). Approaching this issue from the perspective of industrial ecology, with a circular economy framework that involves design of products that facilitate reuse, recycling and conservation needs urgent attention from researchers and policy-makers alike.

Whether the use of increasing above-ground stock or the extraction of minerals from the deep ocean are to be successful in expanding resources and diversifying supply chains is still unclear. However, in considering such unconventional resources the full life cycle impacts should be clearly assessed, considered and debated with the public in order to identify clearly preferred and sustainable futures.

The work of the US Critical Materials Institute and other such organizations needs to be undertaken with a global vision of international development and a willingness to work in partnership with countries who might otherwise not be in political congruence with each other. The US National Science Foundation already has an active office in Beijing and research collaboration through such conduits for rare earths should be encouraged. Similarly, the strained relations between the United States and Bolivia could 
benefit from a sincere willingness to cooperate on developing the Uyuni salt flats where the first pilot processing plant has just started operations this year.

Such outreach should also be a prelude to a broader international treaty on mineral supply security that fosters cooperation. Diplomatic capital should be invested in such a treaty for managing important product minerals in synch with the efforts such as the recently agreed Minamata Convention on Mercury which is focused on limiting the use of a polluting element (United Nations Environment Programme, 2013).

All planetary processes and indeed industrial development is ultimately dependent on elemental flows. Inefficient harnessing of such resources dictated by nationalism can hamper global development and deserves an international response. The most economically and ecologically efficient means of harnessing these materials should be an international priority. Surely such essential resources that have the potential to literally enlighten the world should be a means of catalysing cooperation rather than conflict.

\section{ACKNOWLEDGEMENTS}

The authors would like to acknowledge the useful contributions of the reviewers in improving the chapter from the original submission. Part of the lead author`s time on this publication and associated research has been made possible through the Japan Society for the Promotion of Sciences Grant-in-Aid 26701014.

\section{REFERENCES}

Ali, S. (2014) Social and Environmental Impact of the Rare Earth Industries. Resources, 3, 123-134.

Alonso, E., Sherman, A. M., Wallington, T. J., Everson, M. P., Field, F. R., Roth, R. \& Kirchain, R. E. (2012) Evaluating Rare Earth Element Availability: A Case with Revolutionary Demand from Clean Technologies. Environmental Science \& Technology, 46, 3406-3414. 
American Physical Society \& The Materials Research Society (2011) Energy Critical Elements: Securing Materials for Emerging Technologies. APS Panel on Public Affairs \& the Materials Research Society.

Bauer, D., Diamond, D., Li, J., Sandalow, D., Telleen, P. \& Wanner, B. (2010) Critical Materials Strategy. Washington: US Department of Energy

Binnemans, K., Jones, P. T., Blanpain, B., Van Gerven, T., Yang, Y., Walton, A. \& Buchert, M. (2013) Recycling of rare earths: a critical review. Journal of Cleaner Production, 51, 1-22.

Buchert, M., Manhart, A., Bleher, D. \& Pingel, D. (2012) Recycling critical raw materials from waste electronic equipment. Darmstadt, Germany: Öko-Institut e.V.

Corder, G. D., Golev, A., Fyfe, J. \& King, S. (2014) The Status of Industrial Ecology in Australia: Barriers and Enablers. Resources, 3, 340-361.

Corder, G. D., Mclellan, B. C., Bangerter, P. J., Van Beers, D. \& Green, S. R. (2012a) Engineering-in sustainability through the application of SUSOP ${ }^{\circledR}$. Chemical Engineering Research and Design, 90, 98-109.

Corder, G. D., Mclellan, B. C. \& Green, S. R. (2012b) Delivering solutions for resource conservation and recycling into project management systems through SUSOP ${ }^{\circledR}$. Minerals Engineering, 29 , 47-57.

Davis, R. \& Franks, D. M. (2014) Costs of Company-Community Conflict in the Extractive Sector.: Corporate Social Responsibility Initiative Report No. 66. Cambridge, MA: Harvard Kennedy School.

Ellen Macarthur Foundation (2012) Circular Economy [Online]. Available: http://www.ellenmacarthurfoundation.org/circular-economy [Accessed 29 September 2014].

Ellis, D. V. \& Macdonald, V. I. (1998) Rapid preliminary assessment of seabed biodiversity for the marine and coastal mining industries. Marine Georesources \& Geotechnology, 16, 307-319.

EPA (2012) Rare Earth Elements: A Review of Production, Processing, Recycling, and Associated Environmental Issues. Cincinnati, OH: US Environmental Protection Agency. 
Ernest and Young (2014) Business risks facing mining and metals 2014-2015.

European Commission (2010) Critical Raw Materials for the EU. Report of the Ad-hoc Working Group on defining critical raw materials. European Commission.

Ferron, C. J. \& Henry, P. (2013) A review of the recycling of rare earth metals. Rare Earth Elements: Proceedings of the 52nd Conference of Metallurgists (COM). October 27-31, 2013. Montreal, Quebec, Canada: Canadian Institute of Mining, Metallurgy and Petroleum.

Franks, D., Davis, R., Bebbington, A., Ali, S., Kemp, D. \& Scurrah, M. (2014) Conflict translates environmental and social risk into business costs. Proceedings of the National Academy of Sciences of the United States of America, in press.

Fraser Institute (2013) Survey of Mining Companies 2013. In: MCCAHON, K. (ed.). The Fraser Institute. Geng, Y., Fu, J., Sarkis, J. \& Xue, B. (2012) Towards a national circular economy indicator system in China: an evaluation and critical analysis. Journal of Cleaner Production, 23, 216-224.

Government of Japan (2013) Basic Plan on Ocean Policy [April, 2013] (in Japanese). In: POLICY, H. F. O. (ed.). Tokyo: Government of Japan.

Graedel, T., Allwood, J., Birat, J.-P., Buchert, M., Hagelüken, C., Reck, B. K., Sibley, S. F. \& Sonnemann, G. (2011) Recycling rates of metals: A status report, United Nations Environment Programme.

Gupta, C. K. \& Krishnamurthy, N. (2005) Extractive metallurgy of rare earths, CRC Press.

Hoenderdaal, S., Tercero Espinoza, L., Marscheider-Weidemann, F. \& Graus, W. (2013) Can a dysprosium shortage threaten green energy technologies? Energy, 49, 344-355.

ICMM (2003) International Council on Mining and Metals 10 Principles [Online]. International Council on Mining and Metals 10 Principles. Available: http://www.icmm.com/ourwork/sustainable-development-framework/10-principles [Accessed 3 June 2013]. IEA (2010) The Energy Development Index [Online]. Paris: International Energy Agency. Available: http://www.iea.org/weo/development index.asp [Accessed September 5 2011]. 
IIED (2002) Breaking New Ground: The Report of the Mining, Minerals and Sustainable Development Project. International Institute for Environment and Development and World Business Council for Sustainable Development,.

Kanagawa, M. \& Nakata, T. (2008) Assessment of access to electricity and the socio-economic impacts in rural areas of developing countries. Energy Policy, 36, 2016-2029.

Kato, Y., Fujinaga, K., Nakamura, K., Takaya, Y., Kitamura, K., Ohta, J., Toda, R., Nakashima, T. \& Iwamori, H. (2011) Deep-sea mud in the Pacific Ocean as a potential resource for rare-earth elements. Nature Geosci, 4, 535-539.

Martino, S. \& Parson, L. M. (2012) A comparison between manganese nodules and cobalt crust economics in a scenario of mutual exclusivity. Marine Policy, 36, 790-800.

Mason, C., Paxton, G., Parr, J. \& Boughen, N. (2010) Charting the territory: Exploring stakeholder reactions to the prospect of seafloor exploration and mining in Australia. Marine Policy, 34, 1374-1380.

May, D., Prior, T., Cordell, D. \& Giurco, D. (2012) Peak Minerals: Theoretical Foundations and Practical Application. Natural Resources Research, 21, 43-60.

Mclellan, B., Corder, G. \& Ali, S. (2013) Sustainability of Rare Earths-An Overview of the State of Knowledge. Minerals, 3, 304-317.

Mclellan, B., Zhang, Q., Farzaneh, H., Utama, N. A. \& Ishihara, K. N. (2012) Resilience, Sustainability and Risk Management: A Focus on Energy. Challenges, 3, 153-182.

Mclellan, B. C. (2014) Sustainability of deep ocean resources. 5th International Conference on a Sustainable Future for Human Security. Bali, Indonesia.

Mclellan, B. C. (2015) Sustainability and design considerations for critical minerals in clean energy technologies. In: SHIBATA, J. \& AHN, J.-W. (eds.) The 13th Japan / Korea International Symposium on Resources Recycling and Materials Science. Kyoto, Japan: The Resource Processing Society of Japan and Korea Institute of Geoscience and Mineral Resources. 
Moura Bernardes, A., Espinosa, D. C. R. \& Tenório, J. a. S. (2003) Collection and recycling of portable batteries: a worldwide overview compared to the Brazilian situation. Journal of Power Sources, 124, 586-592.

Nautilus Minerals (2013) Nautilus Minerals Inc. - Solwara I Project [Online]. Toronto. Available: http://www.nautilusminerals.com/s/Projects-Solwara.asp [Accessed April 8 2013].

Nekuda Malik, J. A. (2015) China eliminates rare-earths quotas. MRS Bulletin, 40, 206-207. Seredin, V. V., Dai, S., Sun, Y. \& Chekryzhov, I. Y. (2013) Coal deposits as promising sources of rare metals for alternative power and energy-efficient technologies. Applied Geochemistry, 31, 111.

Sharma, R., Nagendernath, B., Valsangkar, A. B., Parthiban, G., Sivakolundu, K. M. \& Walker, G. (2000) Benthic Disturbance and Impact Experiments in the Central Indian Ocean Basin. Marine Georesources \& Geotechnology, 18, 209-221.

Siddiquie, H. N., Gujar, A. R., Hashimi, N. H. \& Valsangkar, A. B. (1984) Superficial mineral resources of the Indian Ocean. Deep Sea Research Part A. Oceanographic Research Papers, 31, 763-812.

Skirrow, R., Huston, D., Mernagh, T., Thorne, J., Dulfer, H. \& Senior, A. (2013) Critical commodities for a high-tech world: Australia's potential to supply global demand. Geoscience Australia, Canberra.

Tanskanen, P. (2013) Management and recycling of electronic waste. Acta Materialia, 61, 1001-1011. Tharumarajah, R. \& Koltun, P. (2011) Cradle to gate assessment of environmental impact of rare earth metals. ALCAS Conference 2011. Melbourne: Australian Life Cycle Assessment Society. UNEP (2013) Metal Recycling: Opportunities, Limits, Infrastructure. A Report of the Working Group on the Global Metal Flows to the International Resource Panel. Reuter, M. A.; Hudson, C.; van Schaik, A.; Heiskanen, K.; Meskers, C.; Hagelüken, C.

United Nations Environment Programme (2013) Minamata Convention on Mercury-Text and Annexes. UNEP Geneva, Switzerland.

USDOE (2012) Critical Materials Strategy. Washington D.C.: United States Department of Energy. 
USGS (2013) Mineral Commodity Summaries 2013. Washington: United States Geological Survey.

USGS (2015) Mineral Commodity Summaries 2015. Washington: United States Geological Survey.

Williard, N., He, W., Hendricks, C. \& Pecht, M. (2013) Lessons Learned from the 787 Dreamliner Issue on Lithium-Ion Battery Reliability. Energies, 6, 4682. 